\title{
Histologia da pele da carpa prateada (Hypophtalmichthys molitrix) e testes de resistência do couro
}

\author{
Maria Luiza Rodrigues de Souza1, Leandro Cesar Godoy², Hamilton Torres Kozuki², Jorge de \\ Matos Casaca ${ }^{3}$, Doroty Mesquita Dourado 4 , Manuel Antonio Chagas Jacinto ${ }^{5}$
}

\footnotetext{
${ }^{1}$ Depto de Zootecnia - Universidade Estadual de Maringá. Av. Colombo 5790, CEP: 87020-900, Maringá - PR.

2 Graduação em Zootecnia da Universidade Estadual de Maringá. Participante do programa PIBIC.

3 Pós-graduação em Aqüicultura - CAUNESP - Jaboticabal - SP.

${ }^{4}$ Centro de Ciências Biológicas, Agrárias e da Saúde da Universidade para o Desenvolvimento do Estado e da Região do Pantanal (UNIDERP)

${ }^{5}$ Embrapa Gado de Corte. Campo Grande - MS.

Apoio: Secretaria Especial de Aqüicultura e Pesca da Presidência da República.
}

RESUMO - Este estudo foi realizado com os objetivos de analisar a histologia da pele e avaliar a influência da técnica de curtimento e da posição da retirada do corpo-de-prova sobre a qualidade da pele de carpa prateada (Hypophtalmichthys molitrix). Vinte e três peixes foram insensibilizados para retirada das peles para curtimento. Amostras referentes a três peixes foram fixadas em formol 10\%. Após a inclusão em parafina, foram cortadas com aproximadamente $5 \mathrm{~mm}$ de espessura coradas pela técnica de hematoxilina-eosina (HE). Após o curtimento das peles, foram retirados os corpos-de-prova para os testes de resistência. Os testes foram realizados com dinamômetro EMIC, com velocidade de afastamento entre cargas de $100 \pm 20 \mathrm{~mm} / \mathrm{mm}$, em ambiente climatizado a $23^{\circ} \mathrm{C}$ e umidade relativa do ar de $50 \%$ por um período de 24 horas. As peles curtidas com sais de cromo apresentaram maior resistência à tração $\left(16,96 \mathrm{~N} / \mathrm{mm}^{2}\right)$, ao alongamento $(51,49 \%)$ e ao rasgamento progressivo $\left(16,75 \mathrm{~N} / \mathrm{mm}\right.$ ) quando comparadas àquelas curtidas sem sais de cromo (tração $=9,12 \mathrm{~N} / \mathrm{mm}^{2}$, alongamento $=17,48 \%$ e rasgamento $=11,36 \mathrm{~N} / \mathrm{mm})$. O sentido da retirada dos corpos-de-prova não interferiu nas características de tração, elongação, carga de ruptura, rasgo, força máxima e carga de força. A técnica de curtimento (utilizando ou não sais de cromo) influencia a resistência das peles de carpa prateada. A técnica empregando os sais de cromo proporciona maior resistência ao couro.

Palavras-chave: fibras colágenas, Hypophtalmichthys molitrix, pele de peixe, qualidade do couro, teste físico-mecânico

\section{Histology of silver-plated carp skin (Hypophtalmichthys molitrix) and leather resistance tests}

BSTRACT - The objectives of this trial were to analyze the skin histology and to evaluate the influence of tanning technique and the direction removal of samples on skin quality of silver-plated carp (Hypophtalmichthys molitrix). Twenty-three fishes were sacrificed and the skin was removed for tanning. Samples of three fishes were settled in formol $10 \%$ and, after inclusion in paraffin, the samples were cut with approximately $5 \mathrm{~mm}$ of thickness and colored by the hematoxylin-eosin technique (HE). After skin tanning, the samples were removed for resistance tests. The tests were done with EMIC dynamometer, at removal speed of $100 \pm 20 \mathrm{~mm} / \mathrm{mm}$, in a climatized environment $\left(23^{\circ} \mathrm{C}\right)$ and $50 \%$ air relative humidity for 24 -h period. The skins tanned with chromium salts showed greater resistance to tensile strenght $\left(16.96 \mathrm{~N} / \mathrm{mm}^{2}\right)$, elongation $(51.49 \%)$ and progressive tearing $\left(16.75 \mathrm{~N} / \mathrm{mm}\right.$ ) than those tanned without chromium salts (tensile strenght $=9.12 \mathrm{~N} / \mathrm{mm}^{2}$, elongation $=17.48 \%$ and 11.36 progressive tearing $=\mathrm{N} / \mathrm{mm}$ ). No effect of direction removal of samples on tensile strenght, elongation, rupture load, progressive tearing, maximum force, and force load was observed. The tanning technique (with or without chromium salts) affect the resistance of the silver-plated carp skin. The technique with chromium salts results in bigger resistance to leather.

Key Words: collagen fibers, fish skin, Hypophtalmichthys molitrix, leather quality, physical and mechanical tests

\section{Introdução}

Com o significativo crescimento da piscicultura nos últimos anos, algumas espécies têm alcançado grande destaque por serem economicamente exploráveis e fornecerem à população uma alternativa de alimento de elevado teor protéico, além de possibilitar o aproveitamento de subprodutos do seu abate, como a pele, que pode ser curtida e utilizada na confecção de artefatos, vestuários e até mesmo de calçados.

O sucesso de uma criação racional de peixes depende essencialmente da escolha da espécie, de modo que atenda 
às exigências do mercado consumidor, propicie elevada produção por área em menor tempo de cultivo, com baixo custo, e apresente potencial para a industrialização.

Portanto, é interessante a utilização de espécies rústicas, de rápido crescimento e com ótimo desempenho para ganho de peso. Entre as recomendadas para o policultivo, encontram-se as carpas zooplanctóforas, herbívoras e/ou filtradoras. No Brasil, a Região Sul destaca-se pela produção de peixes, sobretudo o policultivo de carpas. No estado de Santa Catarina, as espécies mais comuns são as carpas (61\%) e as tilápias (23\%), espécie normalmente utilizada juntamente no policultivo. Nas áreas de influência das indústrias beneficiadoras de peixes, no entanto, as tilápias são as espécies principais (Poli et al., 2000).

Considerando a possibilidade de utilização de policultivos com espécies que possam incrementar a receita do produtor e a utilização dos subprodutos gerados pelo abate, a pele caracteriza-se como um dos principais subprodutos, atingindo de 4,5 a $10 \%$ do peso do animal.

Segundo Ingram \& Dixon (1994), as peles de peixes são consideradas um couro exótico e inovador, com aceitação geral em vários segmentos da confecção. Entretanto, para chegar aos grandes atelieres, devem passar por um processo tecnológico que possibilita qualidade superior ou não à pele curtida (couro), dependendo do processo utilizado, das condições de armazenagem até o curtimento, do tempo e dos produtos utilizados no curtimento. Outro aspecto importante é a comprovação da resistência desse couro por testes físico-mecânicos que determinam a qualidade para uso na confecção de vestuários, sapatos ou artefatos em geral.

É importante a análise da arquitetura histológica da derme, que difere quanto à orientação e disposição das fibras colágenas em cada espécie de peixe. As fibras podem estar dispostas em camadas sobrepostas e intercaladas por camadas com orientação contrária das fibras, de forma que as camadas de fibras ficam cruzadas entre si. Complementando essa amarração das fibras colágenas, em muitas peles de peixes encontram-se fibras dispostas perpendicularmente à espessura, parcial ou total da derme (Junqueira et al., 1983; Souza \& Leme dos Santos, 1995; Dourado et al., 1996; Machado, 2001). Almeida (1998) também cita que a análise em microscópio de polarização de corte histológico de peles de muitas espécies indica que os feixes de fibras de colágeno se dispõem em ângulos próximos a $45^{\circ}$ ao longo da pele, cruzando com os perpendiculares, podendo ocorrer uma diversidade na disposição e orientação das fibras colágenas entre as diferentes espécies de peixes. Esta caracterização quanto à arquitetura histológica da pele define a qualidade da resistência do couro do peixe (Junqueira et al., 1983; Souza, 2003). Nas peles de mamíferos em geral, as fibras colágenas são dispostas de modo a formarem um entrelaçamento de fibras com a aparência de rede, resultando em um couro com maior resistência. O conhecimento da estrutura histológica da pele e os testes físico-químicos e físicomecânicos possibilitam análise completa da qualidade de resistência do couro de peixe.

Apesar de as peles de peixes diferirem quanto à estrutura dérmica, à disposição, à orientação e à constituição das fibras colágenas, para determinação dos testes de resistência, existem normas específicas somente para couros de mamíferos. Além disso, a área útil do couro dificulta a retirada dos corpos-de-prova, dificultando as análises de resistência.

Considerando as limitações para comparação dos resultados obtidos em couros de peixes, analisou-se a histologia da pele da carpa prateada (Hypophtalmichthys molitrix) e avaliou-se a resistência (em função dos sentidos longitudinal e transversal ao comprimento do couro) das peles curtidas com e sem sais de cromo.

\section{Material e Métodos}

Para a análise da estrutura histológica e da resistência do couro, foram utilizados 23 peixes (carpa prateada, Hypophtalmichthys molitrix) provenientes de viveiros, levados para uma unidade de processamento de pesquepague. Os peixes foram abatidos por insensibilização e choque térmico (caixas isotérmicas com gelo moído e água na proporção 1:1).

As análises histológicas foram realizadas no Laboratório de Pesquisa em Histopatologia da UNIDERP, MS. O curtimento das peles e as análises de resistência do couro foram realizados no laboratório de processamento de peles de peixes e demais espécies de pequeno e médio porte da Universidade Estadual de Maringá, PR.

As amostras de pele foram retiradas das regiões dorsal média (RDM) e mediana (RML) sobre a linha lateral do lado esquerdo. Amostras referentes a três peixes foram fixadas em formol $10 \%$, incluídas em parafina, cortadas a aproximadamente $5 \mathrm{~mm}$ de espessura e coradas pela técnica de hematoxilina-eosina (HE).

Os cortes histológicos foram analisados pela técnica de microscopia de luz, selecionados e fotomicrografados em fotomicroscópio Axiophot Zeiss.

Para o processo de curtimento, foram utilizadas 20 carpas de 1 a $2 \mathrm{~kg}$. As peles foram retiradas com auxílio de um alicate especial de ponta fina, pesadas individualmente, 
identificadas e congeladas. Posteriormente, foram descongeladas à temperatura ambiente e identificadas com auxílio de miçangas coloridas de tamanhos diferentes, fixadas à pele por meio de uma linha mercê $n^{\circ} 40$.

O processo de curtimento constou das etapas de remolho, caleiro, desencalagem, purga, píquel, curtimento, neutralização, recurtimento, tingimento, engraxe, secagem e acabamento. Com base nas etapas do processo de curtimento e considerando a necessidade de adaptações em tempo e quantidades de produtos químicos, adotou-se um padrão de curtimento proposto por Souza (2003, 2004), utilizando-se os seguintes produtos: tensoativo MK IV, sulfeto de sódio, cal hidratada, Koropon MK SC, Kalplex, ácido fórmico, Chromosal B, tanino vegetal (Weibull), bicarbonato de sódio, corante e óleos sulfitado e sulfatado.
Após o curtimento das peles, foram retirados corposde-prova para determinação da resistência à tração, ao alongamento (ABNT -NBR 11041, 1997) e ao rasgamento progressivo (ABNT-NBR 11055, 1997). Para avaliação comparativa dos couros em função do sentido do corpo-deprova, foram retiradas oito amostras longitudinalmente e transversalmente (de um dos lados do peixe) ao comprimento do corpo do peixe, conforme metodologia aplicada por Souza et al. (2002) (Figura 1).

Para a análise comparativa do curtimento com e sem sais de cromo $(\mathrm{n}=9)$, foram retirados apenas corpo-deprova no sentido longitudinal.

Os testes foram realizados com dinamômetro EMIC, com velocidade de afastamento entre cargas de $100 \pm 20 \mathrm{~mm} / \mathrm{mm}$, em ambiente climatizado a $23^{\circ} \mathrm{C}$ e umidade relativa do ar de $50 \%$, por um período de 24 horas, conforme ABNT (NBR,

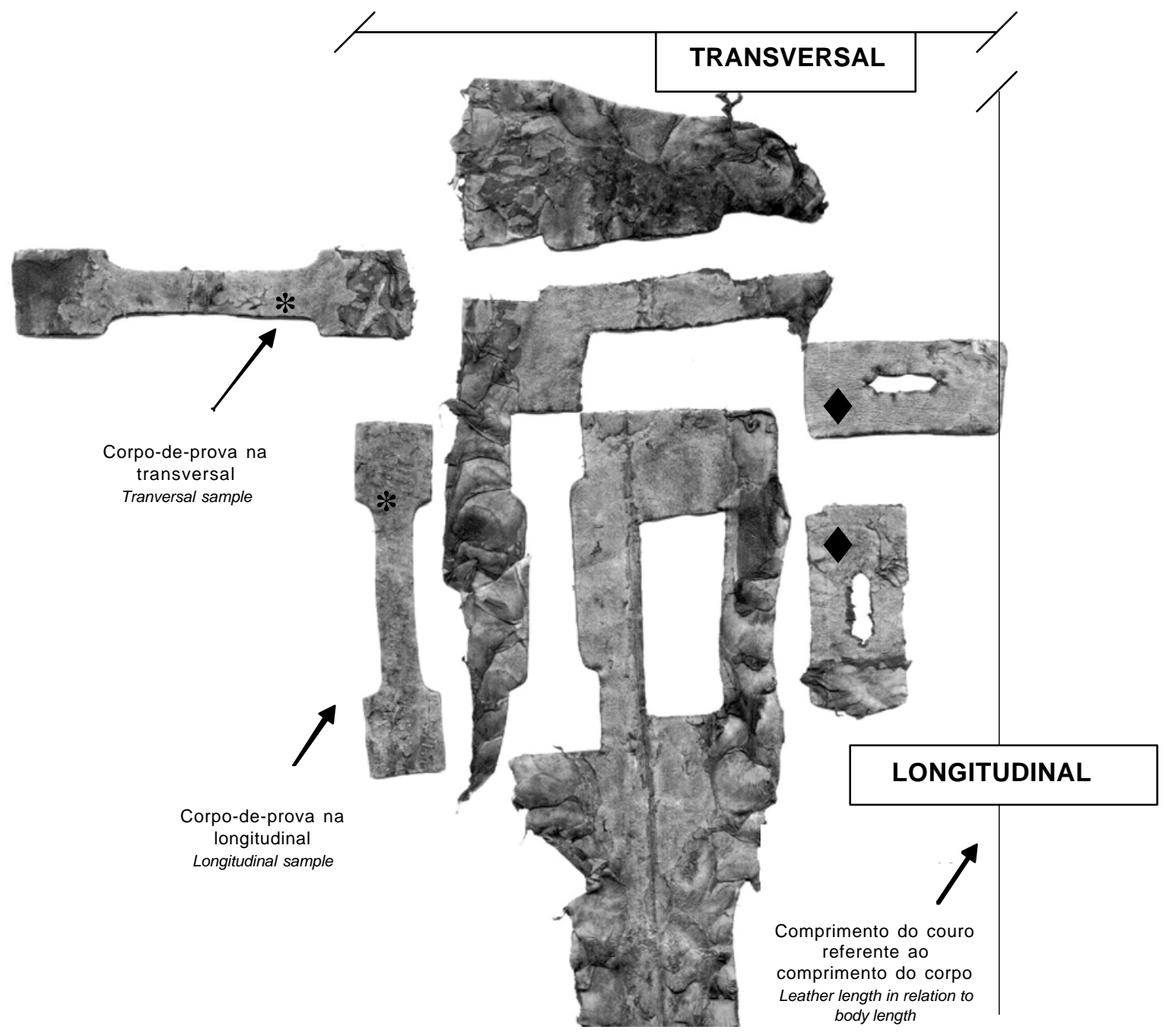

Figura 1 - Corpos-de-prova do couro da carpa prateada, conforme metodologia aplicada por Souza et al. (2002), em couro de carpaespelho. * corpo-de-prova para testes de tração e alongamento; corpo-de-prova para teste do rasgamento progressivo.

Figure 1 - Leather samples of for silverplated carp leather, according to Souza et al. (2002) methodology in leather of mirror carp. * sample for tests of traction and elongation; samples for tests of progressive tearing. 
10455, 1988). Antes dos testes físico-mecânicos, foram determinadas as medidas de espessura das amostras de acordo com ABNT (NBR 11062, 1997).

As análises de resistência dos couros foram feitas em um delineamento experimental inteiramente casualizado, com dois tratamentos para análise em função do sentido ( $\mathrm{SL}=$ longitudinal e $\mathrm{ST}=$ transversal) e dois para análise da técnica de curtimento com e sem sais de cromo $(\mathrm{CC}=\mathrm{com}$ sais de cromo; $\mathrm{SC}=$ sem sais de cromo).

Os resultados dos testes físico-mecânicos foram submetidos à análise de variância e as médias comparadas pelo teste Tukey a $5 \%$ de probabilidade (Banzatto \& Kronka, 1995).

\section{Resultados e Discussão}

A histologia da pele da carpa prateada (Hypophtalmichthys molitrix) assemelha-se à de outros peixes teleósteos quanto à presença da epiderme e derme, apresentando ainda a hipoderme, camada que une a pele à musculatura.

A epiderme é composta de camadas sobrepostas de células epiteliais e células mucosas e claviformes. Segundo Storer \& Usinger (1978), a epiderme é composta por células epiteliais aplainadas, dispostas em subcamadas que contêm células produtoras de muco e pigmentos. Segundo Pasos (2002), na epiderme encontram-se as células mucosas que produzem mucina, uma glicoproteína formadora do muco (secreção lubrificante).

De acordo com Ralphs \& Benjamin (1992), as células claviformes, facilmente distinguidas das células mucosas, são glândulas grandes e unicelulares, secretoras de um feromônio (substância alarme) que induz a reação de fuga dos peixes.

$\mathrm{Na}$ Figura 2 observa-se que as fibras colágenas posicionadas mais superficialmente na derme da região dorsal média apresentam-se mais espessas e em forma de pena (peniforme). À medida que as fibras colágenas se distanciam da superfície epidérmica, sua espessura e o espaço interfibrilar diminuem.

Souza et al. (2003) analisaram a histologia da pele do pacu (Piaractus mesopotamicus) e observaram que a derme na região dorsal e na linha lateral apresenta feixes de fibras colágenas em camadas sobrepostas, de forma que as fibras de uma camada encontram-se no sentido longitudinal ao comprimento e as da camada seguinte, no sentido longitudinal à altura (largura) do corpo.

Na Figura 3, referente ao corte da derme na região mediana lateral, observam-se duas camadas: uma mais superficial, constituída de tecido conjuntivo frouxo, com poucas fibras colágenas e grande quantidade de fibroblastos, e outra mais compacta ou profunda, que se diferencia quanto à disposição das fibras colágenas da região mediana lateral e da região dorsal média. Na camada mais profunda da região mediana lateral, as fibras colágenas são mais finas e próximas, tornando-se mais espessas e com menor espaço interfibrilar à medida que se aproximam da hipoderme. Nessa região, observa-se o orifício da linha lateral(LL).

$\mathrm{Na}$ derme profunda, as fibras colágenas estão dispostas paralelamente à superfície da pele, enquanto, próximo à camada hipodérmica, nota-se a presença de fibras colágenas transversais (Figura 4). Na parte mais superficial da camada dérmica, as fibras são mais finas e unidas, ao passo que, na região mais central, verificam-se espessura e distanciamento mais padronizados ou uniformes. Na parte mais profunda da derme, próximo à hipoderme, ocorrem feixes de fibras colágenas transversais direcionadas à musculatura esquelética do peixe (seta).

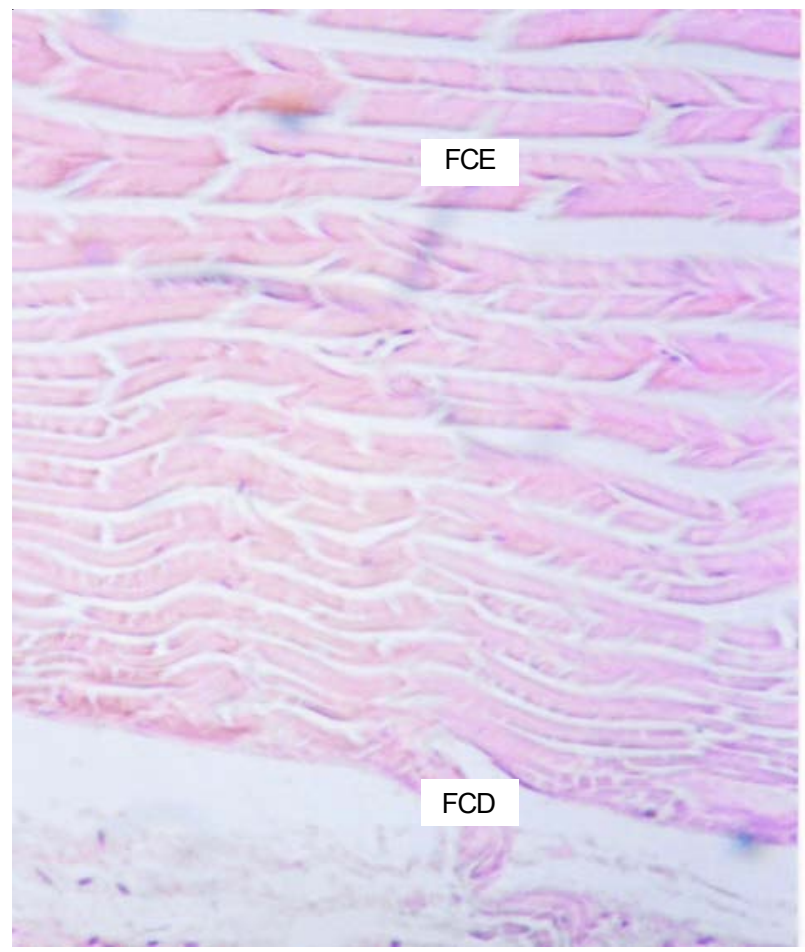

Figura 2 - Fotomicrografia da derme da região dorsal média da carpa prateada (Hypophtalmichthys molitrix). $\mathrm{FCE}$ = fibras colágenas superiores mais espessas; $F C D$ = fibras colágenas mais delgadas. Objetiva: 40X e Coloração HE.

Figure 2 - Photomicrography of the dermis of average dorsal region (RDM) of silver-plated carp (Hypophtalmichthys molitrix). FCE: upper thicker collagen staple fibers; FCD: thinner collagen staple fibers. Objective: $40 \mathrm{X}$ and Coloration: $\mathrm{HE}$. 
De acordo com Junqueira et al. (1983), em todas as espécies de peixes, o colágeno apresenta-se em duas camadas distintas: uma delgada superficial (derme frouxa) e outra espessa e profunda (compacta). A camada profunda é similar em todas as espécies e varia de acordo com a disposição da camada mais superficial.

$\mathrm{Na}$ análise comparativa da pele de carpa prateada (Hypophtalmichthys molitrix) curtida com e sem sais de cromo, não se constatou diferença significativa quanto à espessura dos corpos-de-prova dos couros $(0,61$ a $0,63 \mathrm{~mm}$ ), analisada no sentido longitudinal ao comprimento do peixe. Também não houve diferença significativa quanto à força máxima $(\mathrm{CC}=25,83 \mathrm{Ne} \mathrm{SC}=18,88 \mathrm{~N})$ e a carga de força $(\mathrm{CC}=10,16 \mathrm{~N}$ e $\mathrm{SC}=7,21 \mathrm{~N})$ para os tratamentos.

Os couros curtidos com sais de cromo (CC), em relação aos curtidos sem sais de cromo (SC), apresentaram resistência superior para tração $\left(16,96 \times 9,12 \mathrm{~N} / \mathrm{mm}^{2}\right)$, carga $(104,79$ x 58,81 N), elongação $(51,49$ x 17,48\%) e rasgamento progressivo $(16,75 \times 11,36 \mathrm{~N} / \mathrm{mm})$ (Tabela 1). Almeida (1998) observaram valor de $7,89 \mathrm{~N} / \mathrm{mm}$ de resistência ao rasgamento progressivo em couros de tilápia-do-nilo (Oreochromis niloticus), enquanto Souza et al. (2002) verificaram valor de $8,16 \mathrm{~N} / \mathrm{mm}$ em couros de Piraputanga (Brycon hilarii). Esses valores são inferiores aos obtidos neste trabalho para a carpa prateada.

Os valores de elongação até a ruptura registrados neste experimento foram inferiores aos relatados por Almeida (1998) para tilápia-do-nilo (79\%).

De acordo com Souza et al. (2002), a pele da carpa espelho (Cyprinus carpio specularus) curtida sem sais de cromo e analisada apenas no sentido longitudinal apresentou resistência à tração de $18,75 \mathrm{~N} / \mathrm{mm}^{2}$, ao alongamento de $73,38 \%$ e ao rasgamento progressivo de $12,08 \mathrm{~N} / \mathrm{mm}$, o que comprova superioridade em relação à carpa prateada nas mesmas condições de curtimento.

Segundo Hoinacki (1989), o couro bovino curtido ao cromo deve apresentar resistência de, no mínimo, $9,8 \mathrm{~N} / \mathrm{mm}^{2}$. O couro da carpa prateada curtido com sais de cromo pode ser utilizado na confecção de vestuário, pois apresentou valor médio de resistência à tração de $16,96 \mathrm{~N} / \mathrm{mm}^{2}$, superior ao valor mínimo exigido para confecção de vestuário a partir de couros bovinos.

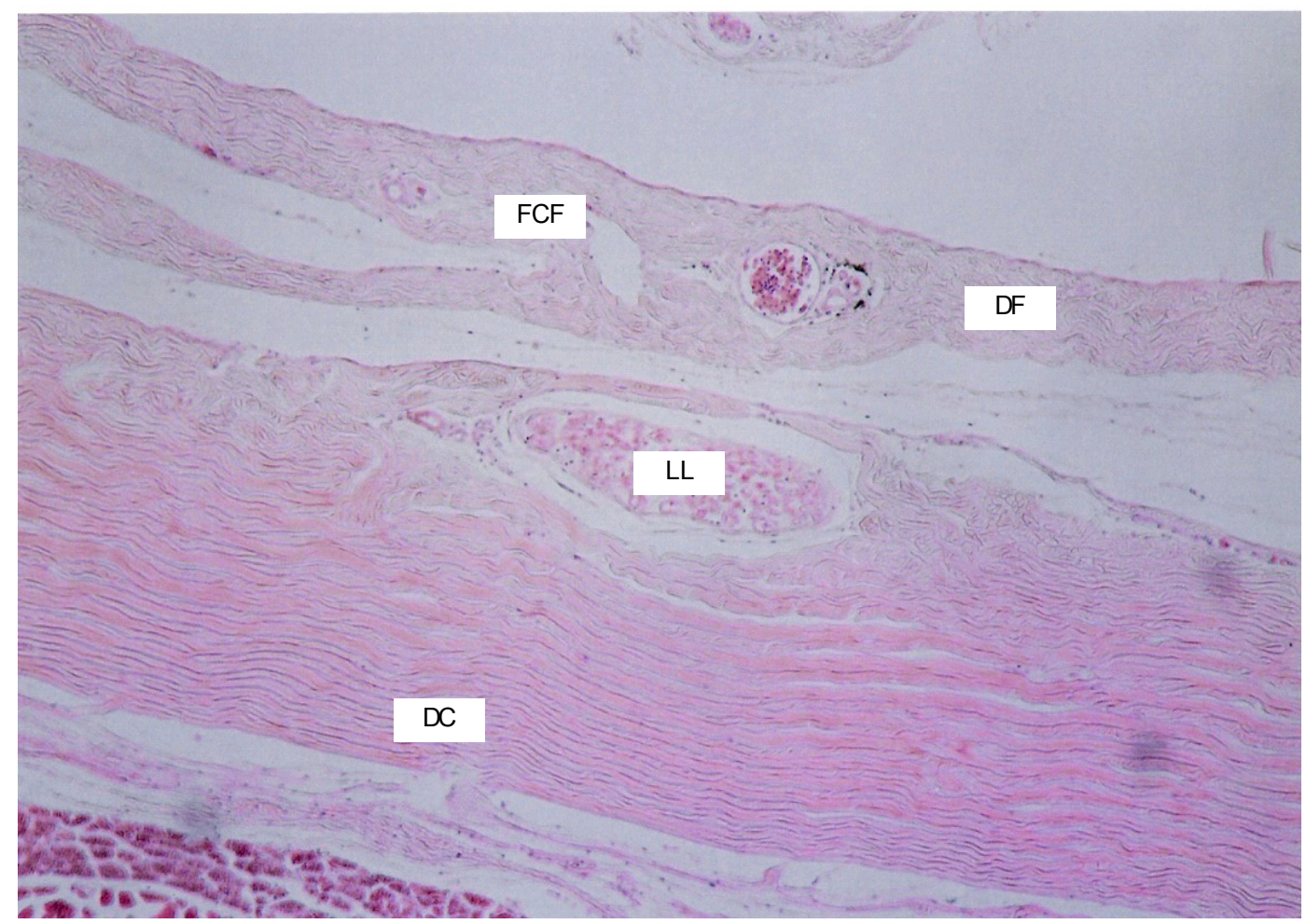

Figura 3 - Fotomicrografia da pele da carpa prateada (Hypophtalmichthys molitrix). Na região média da derme, observa-se o orifício da linha lateral (LL). Duas camadas de derme foram observadas: tecido conjuntivo frouxo (DF) e tecido conjuntivo compacto (DC). Foi observada também a camada dérmica com fibras colágenas transversal espaçadas próximas à hipoderme. FCF = fibras colágenas finas. Objetiva: 40X e Coloração HE.

Figure 3 - Photomicrography of silver-plated carp (Hypophtalmichthys molitrix) skin. In dermis medium region the orifice of the lateral line in observed (LL). Two dermis layers are observed: flabby (DF) and compact (DC). It is observed dermis layer with transversal collagen staple fibers towards to hypodermis. $F C F=$ thinner collagen fibers. $40 \mathrm{X}$ and Coloration: $\mathrm{HE}$. 
A análise comparativa da resistência dos couros da carpa prateada (Hypophtalmichthys molitrix) comprovou efeito significativo $(\mathrm{P}<0,05)$ do sentido ao comprimento do couro sobre a espessura dos corpos-de-prova. A espessura do couro no sentido longitudinal foi superior $(0,61 \mathrm{~mm})$ à obtida no sentido transversal $(0,52 \mathrm{~mm})$.

Não houve diferença significativa para as características de tração, elongação, carga, rasgo, força máxima e carga de força (Tabela 2). Apesar da diferença $(\mathrm{P}<0,05)$ na espessura do corpo-de-prova do couro, não houve influência das características analisadas quando comparados os sentidos longitudinal e transversal ao comprimento do couro do peixe.

Souza (2003), analisando o sentido do couro (transversal e longitudinal) da tilápia-do-nilo (Oreochromis niloticus), observou que o couro possui mais resistência à tração e ao rasgamento progressivo no sentido transver$\operatorname{sal}\left(17,40 \mathrm{~N} / \mathrm{mm}^{2}\right.$ e $\left.20,54 \mathrm{~N} / \mathrm{mm}\right)$ se comparado ao longitudinal $\left(9,13 \mathrm{~N} / \mathrm{mm}^{2}\right.$ e $\left.12,56 \mathrm{~N} / \mathrm{mm}\right)$, ao passo que, no sentido longitudinal, possui elasticidade $(61,65 \%)$ maior que na posição transversal $(58,74 \%)$.

Em pele curtida de pacu (Piaractus mesopotamicus), Souza et al. (2003) observaram diferença na resistência à tração e ao alongamento entre os sentidos longitudinal e transversal ao comprimento do corpo e obtiveram valores superiores no sentido transversal $\left(13,81 \mathrm{~N} / \mathrm{mm}^{2}\right.$ e $76,98 \%$, respectivamente) em relação ao longitudinal $\left(5,93 \mathrm{~N} / \mathrm{mm}^{2} \mathrm{e}\right.$ $52,20 \%$, respectivamente). Os autores relataram ainda que o sentido do couro não teve influência no teste ao rasgamento progressivo. Neste experimento, o sentido do couro da carpa prateada não influenciou essa variável, mas, comparando os couros das duas espécies de peixes, constatou-se que o sentido do couro influenciou a resistência à tração e ao alongamento, que foi superior na carpa prateada, embora, no estudo de Souza et al. (2003), o couro de pacu tenha apresentado maior elasticidade. Todavia, o couro da carpa prateada pode ser considerado com resistência superior a muitos outros couros de peixes. São necessárias, no entanto, apenas algumas adequações para deixar o couro com mais elasticidade, o que é possível por meio da intensificação do tempo e das quantidades de enzimas, óleos, entre outros produtos utilizados no processo de curtimento (Souza, 2003; Souza, 2004).

Segundo Souza (2003), de acordo com a técnica de curtimento aplicada e com a quantidade principalmente

Tabela 1 - Médias dos testes de resistência do couro da carpa submetido a duas técnicas de curtimento Table 1 - Averages of resistance tests of carp leather by two tanning techniques

\begin{tabular}{|c|c|c|c|c|c|c|}
\hline \multirow[t]{2}{*}{$\begin{array}{l}\text { Tratamento do cour } \\
\text { Leather treatment }\end{array}$} & \multicolumn{3}{|c|}{$\begin{array}{l}\text { Tração e alongamento } \\
\text { Traction and elongation }\end{array}$} & \multicolumn{3}{|c|}{$\begin{array}{c}\text { Rasgamento progressivo } \\
\text { Progressive tearing }\end{array}$} \\
\hline & $\begin{array}{c}\text { Carga de ruptura }(\mathrm{N}) \\
\text { Load of rupture }\end{array}$ & $\begin{array}{c}\text { Tração }\left(\mathrm{N} / \mathrm{mm}^{2}\right) \\
\text { Traction }\end{array}$ & $\begin{array}{c}\text { Alongamento }(\%) \\
\text { Elongation }\end{array}$ & $\begin{array}{c}\text { Rasgo }(\mathrm{N} / \mathrm{mm}) \\
\text { Tearing }\end{array}$ & $\begin{array}{c}\text { Força máxima }(\mathrm{N}) \\
\text { Maximum force }\end{array}$ & $\begin{array}{c}\text { Carga de força }(\mathrm{N}) \\
\text { Force load }\end{array}$ \\
\hline $\begin{array}{l}\text { Com sais de cromo } \\
\text { With chromium salt }\end{array}$ & 104,79 & 16,96 & 51,49 & 16,75 & 25,83 & 10,16 \\
\hline $\begin{array}{l}\text { Sem sais de cromo } \\
\text { Without chromium sal }\end{array}$ & 58,81 & 9,12 & 17,48 & 11,36 & 18,88 & 7,21 \\
\hline Teste F & $5,47 *$ & $7,84^{*}$ & $28,31 * *$ & $4,71 *$ & $2,13 \mathrm{~ns}$ & $3,11 \mathrm{~ns}$ \\
\hline CV (\%) & 52,74 & 46,97 & 31,78 & 38,07 & 46,04 & 41,52 \\
\hline
\end{tabular}

ns - não-significativo $(P>0,05) ;{ }^{*}$ Significativo $(P<0,05) ;{ }^{* *}$ Significativo $(P<0,01)$

$n s-$ not significant $(P>0,05) ;{ }^{*}$ Significant $(P<0.05) ;{ }^{*}$ Significant $(P<0.01)$.

Tabela 2 - Médias dos testes de resistência do couro da carpa prateada aplicados em diferentes sentidos de corte no corpo-de-prova Table 2 - Averages of resistance tests of silverplated carp leather by different sample directions

\begin{tabular}{|c|c|c|c|c|c|c|}
\hline \multirow[t]{2}{*}{$\begin{array}{l}\text { Direção do couro } \\
\text { Leather direction }\end{array}$} & \multicolumn{3}{|c|}{$\begin{array}{l}\text { Tração e elongamento } \\
\text { Traction and elongation }\end{array}$} & \multicolumn{3}{|c|}{$\begin{array}{c}\text { Rasgamento progressivo } \\
\text { Progressive tearing }\end{array}$} \\
\hline & $\begin{array}{c}\text { Carga de ruptura }(\mathrm{N}) \\
\text { Rupture load }\end{array}$ & $\begin{array}{c}\text { Tração }\left(\mathrm{N} / \mathrm{mm}^{2}\right) \\
\text { Traction }\end{array}$ & $\begin{array}{c}\text { Elongação }(\%) \\
\text { Elongation }\end{array}$ & $\begin{array}{c}\text { Rasgo }(\mathrm{N} / \mathrm{mm}) \\
\text { Tearing }\end{array}$ & $\begin{array}{l}\text { Forçamáxima }(\mathrm{N}) \\
\text { Maximum force }\end{array}$ & $\begin{array}{c}\text { Carga de força }(\mathrm{N}) \\
\text { Force load }\end{array}$ \\
\hline Longitudinal & 143,60 & 22,78 & 48,23 & 11,63 & 17,98 & 6,82 \\
\hline $\begin{array}{l}\text { Longitudinal } \\
\text { Transversal }\end{array}$ & 90,20 & 17,75 & 53,74 & 10,48 & 14,27 & 5,50 \\
\hline $\begin{array}{l}\text { Transversal } \\
\text { Teste F } \\
\text { CV }(\%)\end{array}$ & $\begin{array}{l}2,48 \mathrm{~ns} \\
58,92\end{array}$ & $\begin{array}{l}1,38 \mathrm{~ns} \\
42,99\end{array}$ & $\begin{array}{l}0,76 \mathrm{~ns} \\
23,77\end{array}$ & $\begin{array}{l}0,49 \text { ns } \\
33,11\end{array}$ & $\begin{array}{l}2,21 \mathrm{~ns} \\
34,57\end{array}$ & $\begin{array}{l}1,88 \mathrm{~ns} \\
35,01\end{array}$ \\
\hline
\end{tabular}




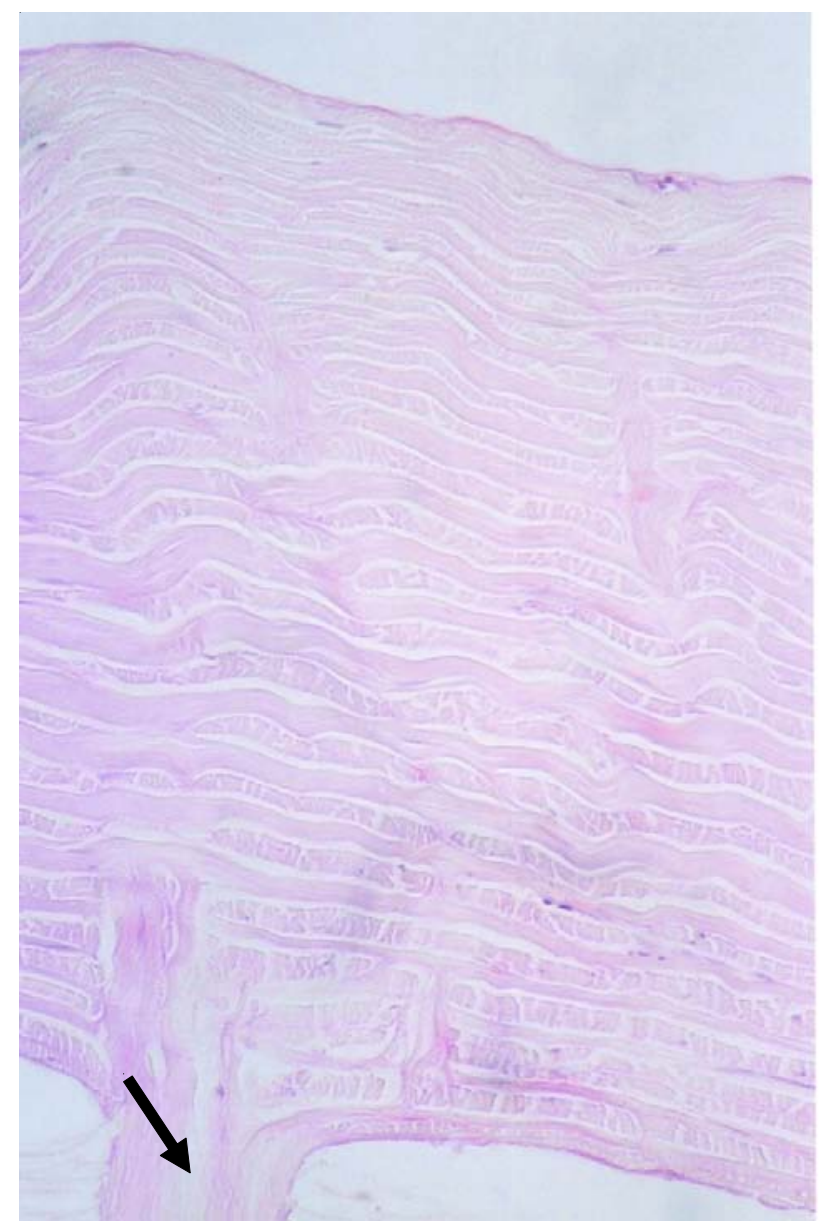

Figura 4 - Fotomicrografia da região mediana da derme da carpa prateada (Hypophtalmichthys molitrix). A seta indica a camada dérmica com fibras colágenas transversais em direção à hipoderme. Objetiva: 40X e Coloração HE.

Figure 4- Photomicrography of the silver-plated carp skin (Hypophtalmichthys molitrix). In dermis of the medium region. It is observed dermis layer with transversal collagen staple fibers in direction to hipodermis. Objective: $40 X$ and Coloration: HE.

de óleos adicionados na etapa de engraxe, obtém-se aumento da flexibilidade e maciez e, conseqüentemente, da resistência ao rasgamento. Esse resultado está relacionado à presença dos óleos que envolvem as fibras colágenas, pois funcionam como lubrificante e evitam a aglutinação das fibras durante a secagem (Hoinacki, 1989; Gutterres, 2001).

Portanto, pode-se inferir que a arquitetura histológica contribui para a resistência do couro dessa espécie, pois, segundo Junqueira et al. (1983), a resistência do couro está relacionada à disposição e orientação das fibras colágenas.

\section{Conclusões}

A pele da carpa prateada é constituída por uma espessa camada dérmica, com feixes de fibras colágenas paralelas e transversais à superfície da pele. A arquitetura das fibras colágenas determina a resistência das peles após o curtimento.

A técnica de curtimento (com ou sem sais de cromo) interfere na resistência das peles de carpa prateada, de modo que a técnica empregando sais de cromo proporciona maior resistência ao couro.

Os couros da carpa prateada não direriram quanto à resistência nos sentidos longitudinal e transversal ao comprimento do corpo.

\section{Agradecimento}

À Secretaria Especial de Aqüicultura e Pesca da Presidência da República, pelo apoio na obtenção dos equipamentos do laboratório de curtimento. À Empresa Trevisan Equipamentos Agroindustriais Ltda, à MK Química do Brasil Ltda, à UNIDERP e à EMIC - Equipamentos e Sistemas de Ensaio Ltda.

\section{Literatura Citada}

ASSOCIAÇÃO BRASILEIRA DE NORMAS TÉCNICAS - ABNT. NBR 10455: climatização de materiais usados na fabricação de calçados e correlatos. Rio de Janeiro, 1988. p.1-2.

ASSOCIAÇÃO BRASILEIRA DE NORMAS TÉCNICAS - ABNT NBR 11062: determinação da espessura. Rio de Janeiro, 1997. p.1. ALMEIDA, R.R. A pele de peixe tem resistência e flexibilidade? Revista do couro, v.127, p.49-53, 1998.

BANZATTO, D.A.; KRONKA, S.N. Experimentação agrícola. 3.ed. Jaboticabal: FUNEP, 1995. 247p.

DOURADO, D.M.; SOUZA, M.L.R.; SANTOS, H.S.L. Structure of cachara skin (Pseudoplatystoma fasciatus) cultivated in rio Miranda. Brazilian Journal of Morphological Science, v.13, n.1, p.148, 1996.

GUTTERRES, M. Distribuição, deposição e interação química de substâncias de engraxe no couro. In: CONGRESSO DA FEDERAÇÃO LATINO-AMERICANA DAS ASSOCIAÇÕES DOS QUÍMICOS E TÉCNICOS DA INDÚSTRIA DO COURO, 15., 2001, Salvador. Anais... Salvador: Federação LatinoAmericana das Associações dos Químicos e Técnicos da Indústria do Couro v.1, p.108-119.

HOINACKI, E. Peles e couros - origens, defeitos, e industrialização. 2.ed.rev. Porto Alegre: Henrique d'Ávila Bertaso, 1989. 319p.

INGRAM, P.; DIXON, G. Fishskin leather: na innovate product. Journal of the Society of Leather Technologists and chemists, v.79, p.103-106, 1994.

JUNQUEIRA, L.C.U.; JOAZEIRO, P.P.; MONTES, G.S. et al. É possível o aproveitamento industrial da pele dos peixes de couro? Tecnicouro, v.5, n.5, p.4-6, 1983.

MACHADO, S.D. Aproveitamento e tecnologia do curtimento de pele de peixe. Campo Grande: Universidade para o Desenvolvimento do Estado e da Região do Pantanal, 2001. $50 \mathrm{p}$. Monografia (Graduação em Ciências Biológicas) Universidade para o Desenvolvimento do Estado e da Região do Pantanal, 2001. 
PASOS, L.A.P. Piel de pescado. Disponível em: http:// www.cueronet.com/exoticas/pescado.htm. Acesso em: 21/11/2002.

POLI, C.R.; GRUMANN, A.; BORGHETTI, J.R. Situação atual da aqüicultura na região sul. In: VALENTI, W.C.; POLI, C.R.; PEREIRA, J.A. et al. (Eds.). Aqüicultura no Brasil. Brasília: CNPq/Ministério da Ciência e Tecnologia, 2000. p.323-351.

SOUZA, M.L.R. Processamento do filé e da pele da tilápia do Nilo (Oreochromis niloticus): aspectos tecnológicos, composição centesimal, rendimento, vida útil do filé defumado e testes de resistência da pele curtida. Jaboticabal: Universidade Estadual Paulista, 2003. 169p. Tese (Doutorado em Aqüicultura) Universidade Estadual Paulista, 2003.

SOUZA, M.L.R. Tecnologia para processamento das peles de peixe. Maringá: Eduem, 2004. 59p (Coleção Fundamentum, 11).

SOUZA, M.L.R.; LEME DOS SANTOS, H.S. Análise microscópica comparada da pele da tilápia (Oreochromis niloticus), da carpa espelho (Cyprinus carpio specularis) e carpa comum (Cyprinus carpio). In: SEMANA SOBRE HISTOLOGIA DE PEIXES, 2., 1995, Jaboticabal. Resumos... Jaboticabal: FUNEP, 1995. p.100-101.
SOUZA, M.L.R; CASACA, J.M.; FERREIRA, I.C. et al. Análise da resistência do couro da carpa espelho curtido sem utilização de sais de cromo. Tecnicouro, v.23, n.8, p.57-69, 2002.

SOUZA, M.L.R.; GANECO, L.N.; NAKAGHI, L.S.O. et al. Histologia da pele do pacu (Piaractus mesopotamicus) e testes de resistência do couro. Acta Scientiarum, v.25, n.1, p.37-44, 2003.

RALPHS, J.R.; BENJAMIN, M. Chondroitin and keratan sulphate in the epidermal club cells of teleosts. Journal of Fish Biology, v.40, p.473-475, 1992. 